\title{
A simple technique for evacuating air bubbles with scum from the bladder dome during transurethral resection of bladder tumor
}

\author{
Hideki Takeshita, Shingo Moriyama, Koji Chiba, Akira Noro \\ Department of Urology, Saitama Red Cross Hospital, Saitama, Japan
}

Videosurgery Miniinv 2014; 9 (4): 619-622

DOI: $10.5114 /$ wiitm.2014.47092

\begin{abstract}
Air bubbles floating in the bladder dome during transurethral resection of a bladder tumor can interfere with the resection, causing intravesical explosion and increasing the potential risk of tumor cell reimplantation. We describe a simple and effective technique for evacuating air bubbles from the bladder dome using routine resectoscopes. First, the beak of the resectoscope is positioned near the air bubble in the bladder dome. Second, the drainage channel of the resectoscope is closed. Third, the irrigation tube is detached from the irrigation channel, and then the channel is opened. Subsequently, the air bubble with entangled scum will be retrogradely aspirated from the beak of the resectoscope to the irrigation channel. Reversing the direction of the water stream enables evacuation of the air bubble with the scum under direct vision. This simple and effective technique may assist surgeons and ensure the safety of patients during a transurethral procedure.
\end{abstract}

Key words: air bubble in the urinary bladder, transurethral endoscopic procedures, intravesical explosion, tumor cell reimplantation.

\section{Introduction}

Transurethral procedures, including transurethral resection of bladder tumor (TURBT), are common urologic procedures performed in daily clinical practice [1-5]. During TURBT, air bubbles in the bladder dome are frequently encountered; these bubbles interfere with the tumor resection. In addition, the air bubble becomes bigger as the gas volume increases because of electroresection or tissue coagulation, occasionally resulting in fire that causes an intravesical explosion. Some cases of bladder rupture due to intravesical explosion have been reported $[2,6]$. Moreover, scum from resected tissue is often entangled in the air bubble in the bladder dome after completion of tumor resection. The scum can contain cancer cells and possibly cause intravesical reimplantation. Generally, absence of air in the bladder dome would be desirable during transurethral surgery.

To keep air apart from the dome, manual suprapubic pressure or changing the patient's position is sometimes effective but is ineffective in several cases such as in obese patients with thick abdominal walls and in elderly patients who have difficulty changing their position because of low cardiopulmonary function. To remove the air in the dome, several maneuvers have been used. Angling the resectoscope ventrally while emptying the bladder and using an Ellik evacuator are easy methods to perform [6] but are often insufficient because of their inherent blind nature. Aspiration of air bubbles through a ureteral catheter is an alternative method [7], but it is slightly complicated because it requires the use of a ureteral catheter and a special endoscope to insert the catheter. 


\section{Aim}

We developed and since then have routinely used a simple technique for evacuating air from the bladder dome effectively without using any special equipment under direct vision. Herein, we describe this technique.

\section{Material and methods}

Between March 2010 and December 2013, 360 consecutive patients underwent TURBT in our institution using the technique we developed to evacuate air from the bladder dome. This technique is performed routinely as part of the daily clinical practice in our institution. It takes only about $1 \mathrm{~min}$ and hardly affects the operative time. The detailed procedure is described in the following paragraphs.

First, the beak of the resectoscope is positioned near the air of the bladder dome under direct vision (Figure $1 \mathrm{~A}-\mathrm{a}$ ). Second, the drainage channel is closed (Figure $1 \mathrm{~A}-\mathrm{b}$ ). Third, the irrigation tube is detached from the irrigation channel, and the channel is opened (Figure 1 A-c). Subsequently, the air bubble will be aspirated from the beak end of the resectoscope into the irrigation channel in a retrograde manner. Water is usually irrigated from the beak of the resectoscope into the bladder and sucked into the drainage holes located at the lateral aspect of the scope, approximately $1 \mathrm{~cm}$ proximal from the beak end (Figure $1 \mathrm{~B}$ ). Reversing the direction of the water stream enables evacuation of the air bubble from the beak of the resectoscope under direct vision (Photos $1 \mathrm{~A}$ and B). The air bubble can be removed nearly completely if the procedure is performed skillfully.

An additional advantage of this technique is that under direct vision, it enables proper removal of scum from resected tissue that is entangled in the air bubble in the dome. Simple hand irrigation through a urethral catheter after completion of surgery or other blind techniques to evacuate the air involve the risk of leaving residual scum that may contain tumor cells (Photos $2 \mathrm{~A}$ and B).

We confirmed that this technique is feasible using resectoscopes manufactured by Karl Storz (UR-27040SL, Tuttlingen, Germany) and Olympus (A22026A, Tokyo, Japan), but it would also be feasible using resectoscopes from other manufacturers
A

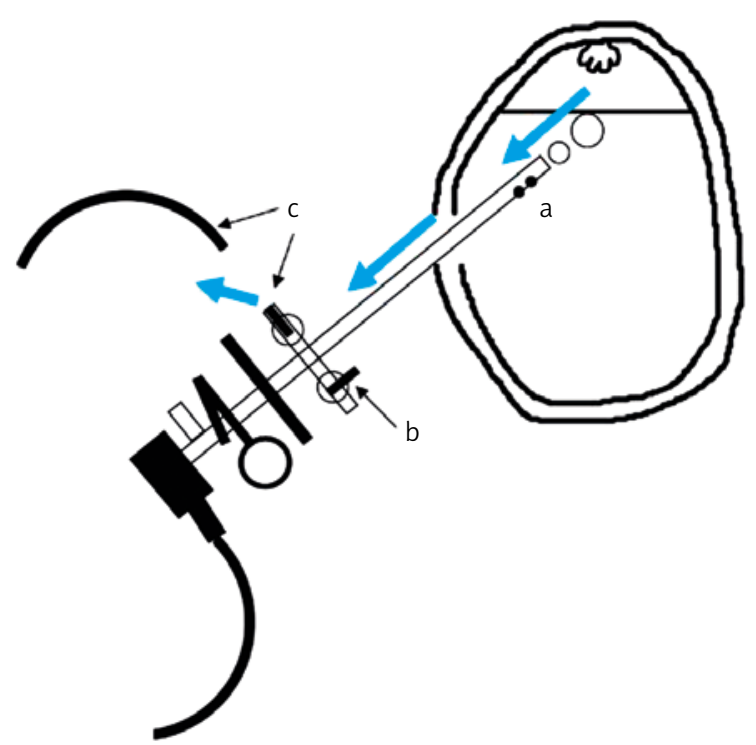

B

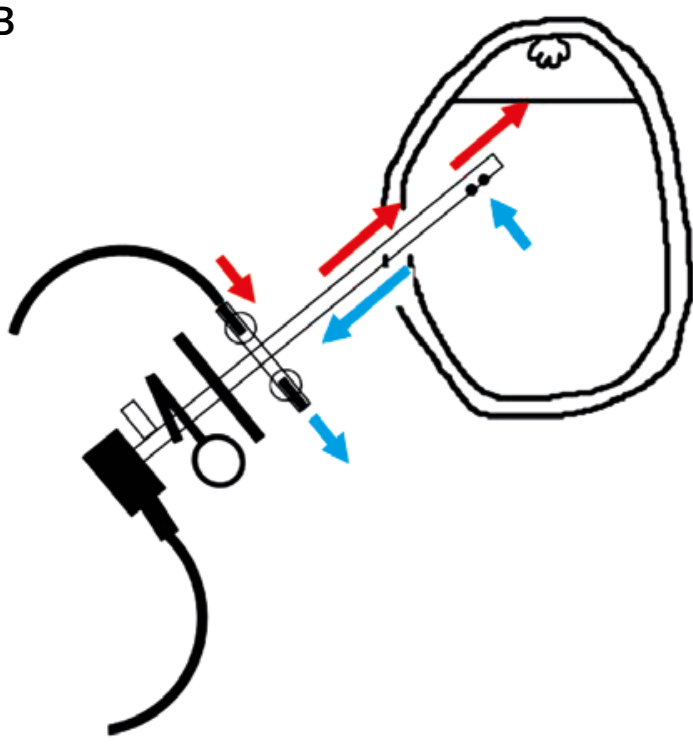

Figure 1. A - First, the beak of the resectoscope is positioned near the air of the bladder dome under direct vision (a). Second, the drainage channel is closed (b). Third, the irrigation tube is detached from the irrigation channel, and the channel is opened (c). B - Water stream through a resectoscope in normal use. Water is irrigated from the beak of the resectoscope and sucked into the drainage holes positioned beside the beak 

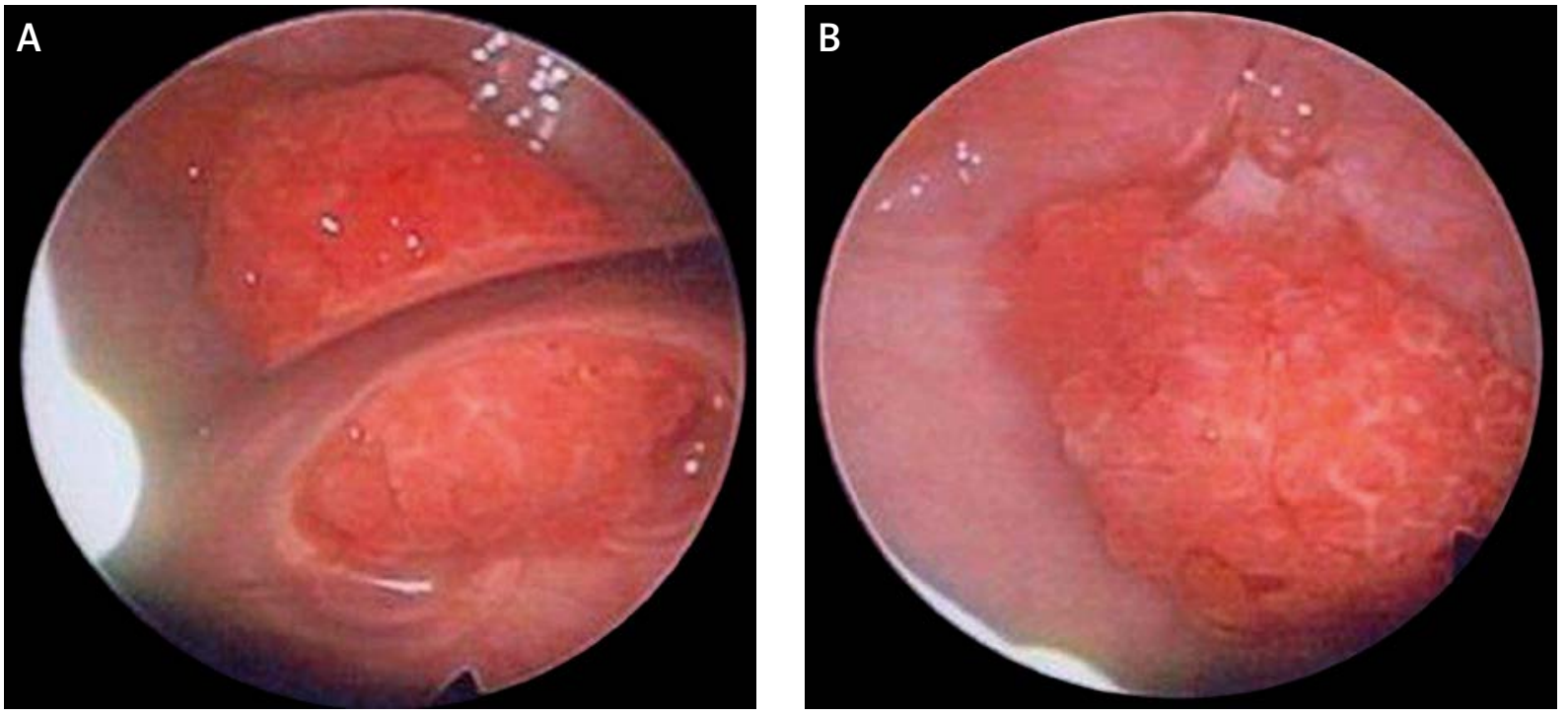

Photo 1. A - A tumor in the urinary bladder dome. Air bubble in the bladder dome obstructing tumor resection. $\mathbf{B}$ - The present technique was used to remove the air bubble, and thereby the tumor was visualized clearly
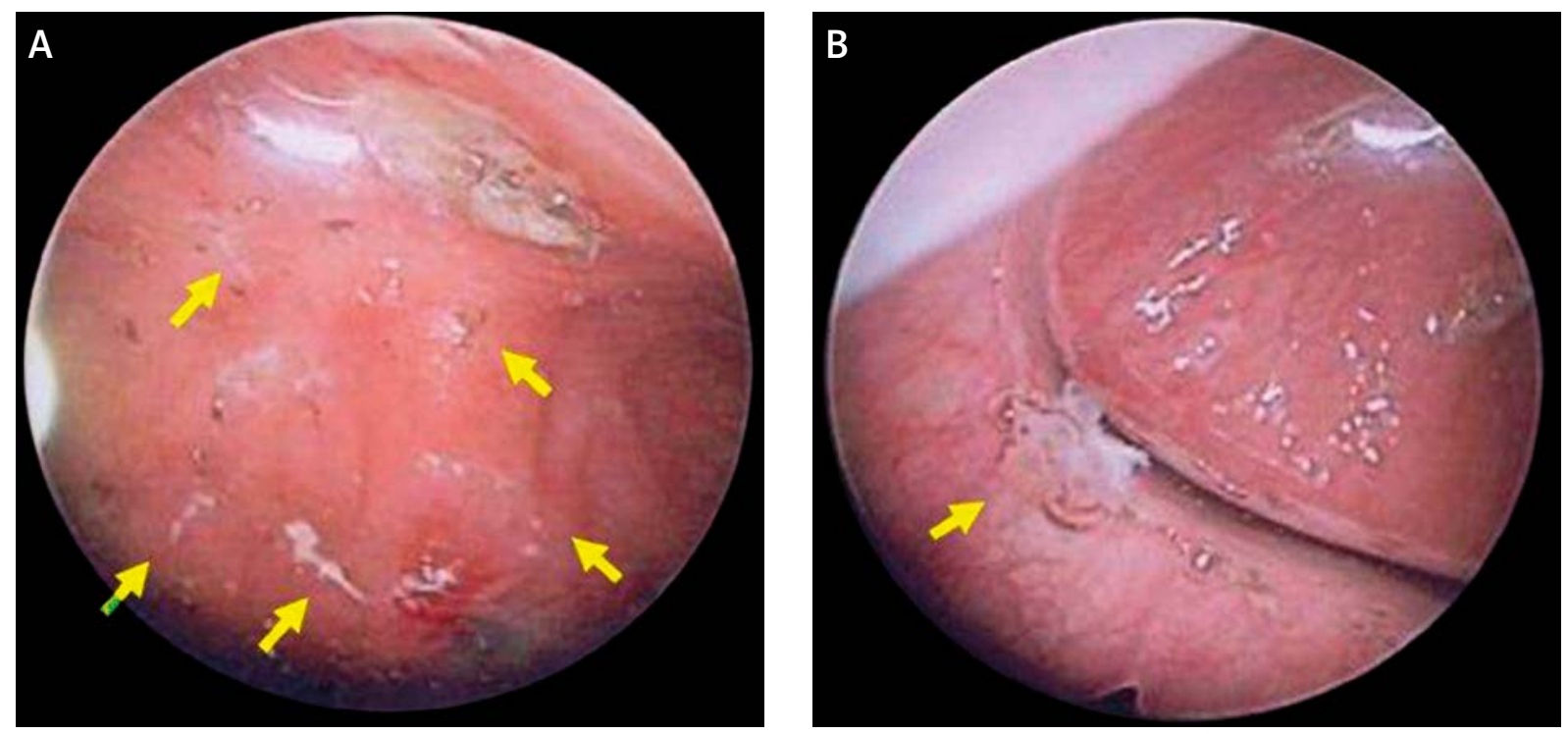

Photo 2. A - Floating scum on the water surface developed by the air bubble in the bladder dome (yellow arrows). B - Excised piece of papillary tumor touching the edge of the air bubble (yellow arrow). This piece was found remaining after completion of transurethral surgery

with similar structures as those manufactured by Karl Storz and Olympus.

\section{Discussion}

This simple and effective technique may be comfortable and easy to use during tumor resection and may result in successful and safer tumor resections. In addition, it may also prevent potential tumor reimplantation. We have already applied this technique in more than 300 transurethral procedures since 2010 [8] and confirmed its simplicity and effectiveness.

Although several cases of bladder rupture due to intravesical explosion have been reported to date $[6,9]$, little is known about the frequency of intravesical explosion, consecutive bladder rupture, and 
consequent tumor dissemination [10, 11]. In addition, whether scum entangled in the air bubble in the bladder dome truly triggers tumor reimplantation is unclear. However, it is a well-known fact that the quality of surgery might affect the recurrence rate after TURBT [12]. By removing the air, the source of explosion and potential scaffold of the tumor, we believe that the quality of TURBT may be improved and may reduce not only the bladder explosion rate but also the tumor recurrence rate. Our future investigation about this technique will elucidate these issues and may enhance the effectiveness of this technique.

\section{Conclusions}

We report a simple technique for effectively evacuating air bubble in the bladder dome using routine transurethral resectoscopes. This technique may not only potentially enhance the safety of performing transurethral surgery but also potentially reduce the risk of bladder cancer recurrence after transurethral surgery.

\section{References}

1. Nieh PT, Marshall FF. Surgery of bladder cancer. In: Campbell-Walsh urology. 9th ed. Wein AJ, Kavoussi LR, Novick AC, et al. (eds.). Saunders, Philadelphia 2007; 2479-505.

2. Traxer O, Pasqui F, Gattegno B, et al. Technique and complications of transurethral surgery for bladder tumours. BJU Int 2004; 94: 492-6.

3. Wu Z, Feng C, Ding Q, et al. Ureteroscopic holmium: YAG laser endopyelotomy is effective in distinctive ureteropelvic junction obstructions. Videosurgery Miniinv 2011; 6: 144-9.

4. Szopiński TR, Sudoł-Szopińska I, Furmanek MI, et al. Degeneration of the symphysis pubis presenting as a submucosal urinary bladder tumour. Videosurgery Miniinv 2012; 7: 55-8.

5. Yoshida S, Kihara K, Takeshita H, et al. A head-mounted display-based personal integrated-image monitoring system for transurethral resection of the prostate. Videosurgery Miniinv 2014; 9: 644-9.

6. Khan A, Masood J, Ghei M, et al. Intravesical explosions during transurethral endoscopic procedures. Int Urol Nephrol 2007; 39: 179-83.

7. Kettunen RC, Hume RH, Han JC. Bubble trouble in bladder tumors. J Urol 1988; 140: 325.

8. Takeshita H, Noro A. Effective technique for evacuating air bubbles from the bladder dome during transurethral resection of bladder tumor [Japanese]. Rinsyo Hinyokika 2010; 64: 174-5.

9. Oğuz G, Subaşı D, Kaya M, et al. Intravesical explosion: a rare complication of transurethral resection of prostate. J Anesth 2013; 27: 145-6.

10. Bartholin J, Krarup T, Walter S, Therkildsen MH. Carcinoma implant in the abdominal wall after transurethral resection of bladder tumors using suprapubic trocar: a report of 3 cases. Scand J Urol Nephrol 1995; 172: 43-4.

11. Ohguchi N, Sakaida N, Okamura A, et al. Extravesical tumor implantation caused by perforation during transurethral resection of a bladder tumor: a case report. Int J Urol 1997; 4: 516-8.

12. Brausi M, Collette L, Kurth K, et al.; the EORTC Genito-Urinary Tract Cancer Collaborative Group. Variability in the recurrence rate at first follow-up cystoscopy after TUR in stage Ta T1 transitional cell carcinoma of the bladder: a combined analysis of seven EORTC studies. Eur Urol 2002; 41: 523-31.

Received: 20.04.2014, accepted: 29.10.2014. 